\title{
Priming in Macaque Frontal Cortex during Popout Visual Search: Feature-Based Facilitation and Location-Based Inhibition of Return
}

\author{
Narcisse P. Bichot ${ }^{1}$ and Jeffrey D. Schall ${ }^{2}$ \\ 1 Laboratory of Neuropsychology, National Institute of Mental Health, National Institutes of Health, Bethesda, Maryland \\ 20892, and 2Vanderbilt Vision Research Center, Department of Psychology, Vanderbilt University, Nashville, Tennessee \\ 37240
}

In popout search, humans and monkeys are affected by trialto-trial changes in stimulus features and target location. The neuronal mechanisms underlying such sequential effects have not been examined. Single neurons were recorded in the frontal eye field (FEF) of monkeys performing a popout search during which stimulus features and target position changed unpredictably across trials.

Like previous studies, repetition of stimulus features improved performance. This feature-based facilitation of return was manifested in the target discrimination process in FEF: neurons discriminated the target from distractors earlier and better with repetition of stimulus features, corresponding to improvements in saccade latency and accuracy, respectively.
The neuronal target selection was mediated by both target enhancement and distractor suppression. In contrast to the repetition of features, repetition of target position increased saccade latency. This location-based inhibition of return was reflected in the neuronal discrimination process but not in the baseline activity in FEF.

These results show adjustments of the target selection process in FEF corresponding to and therefore possibly contributing to changes in performance across trials caused by sequential regularities in display properties.

Key words: visual cortex; vision; attention; selection; eye movements; oculomotor
The selective nature of gaze behavior has been shown elegantly by Yarbus (1967), among other researchers (for review, see Viviani, 1990; Liversedge and Findlay, 2000), by recording the eye movements of subjects viewing natural images. The same type of selective visual behavior is also observed in nonhuman primates such as macaque monkeys (Keating and Keating, 1993; Burman and Segraves, 1994; Sheinberg and Logothetis, 2001). To a large extent, the properties of the stimuli in the image guide behavior, and gaze, like attention, focus on parts of a visual scene that are conspicuous or that are informative with respect to the viewer's goals. For example, items that differ from their neighbors attract gaze. In addition to such bottom-up influences, top-down influences such as knowledge of what to look for affects gaze. Neuronal mechanisms of visual selection based on both bottom-up and top-down factors have been investigated (for review, see Maunsell, 1995; Braun et al., 2001).

The gaze performance of both humans and monkeys is affected by visual experience (Bichot et al., 1996; Bichot and Schall, 1999a; Dorris et al., 1999; McPeek et al., 1999; McPeek and Keller, 2001). An example of such rapid changes in behavior caused by previous experience is the well known priming of popout (Bravo and Nakayama, 1992; Maljkovic and Nakayama, 1994, 1996). This robust effect manifests itself as an improvement of behavioral

\footnotetext{
Received Jan. 2, 2002; revised Feb. 19, 2002; accepted March 8, 2002.

This work was supported by National Eye Institute Grants RO1-EY08890 (J.D.S.) and P30-EY08126 and T32-EY07135 to the Vanderbilt Vision Research Center, and by the National Institute of Mental Health Intramural Research Program. The data were collected while N.P.B. was at Vanderbilt University. J.D.S. is a Kennedy Center Investigator. We thank Drs. Kirk Thompson and Steven Wise for helpful discussion and comments on this manuscript.

Correspondence should be addressed to Dr. Narcisse P. Bichot, Laboratory of Neuropsychology, National Institutes of Health, National Institute of Mental Health, Building 49, Room 1B80, Bethesda, MD 20892-4415. E-mail: bichot@In.nimh.nih.gov. Copyright (C) 2002 Society for Neuroscience $0270-6474 / 02 / 224675-11 \$ 15.00 / 0$
}

performance (e.g., shorter reaction time and higher accuracy) with the repetition of target and/or distractor features or of target position over consecutive trials. Furthermore, this effect has been shown consistently to have a short time course of 5-10 trials, or $\sim 30$ sec. Neuronal mechanisms of such rapid behavioral adjustments during visual search over the course of a few trials have not been investigated.

We have presented behavioral evidence that monkeys exhibit feature-based priming of popout (Bichot and Schall, 1999a). Here, we report results from single-neuron recordings in the frontal eye field (FEF) of monkeys trained to perform popout visual search tasks during which short-term priming is typically observed. We have previously shown that FEF exhibits the characteristics of a visual salience map in which the behavioral relevance of stimuli is represented (for review, see Bichot, 2001a; Thompson et al., 2001). This conclusion was reached based on neuronal modulation in FEF during both bottom-up (Thompson, 2001) and top-down (Bichot, 2001b) visual search tasks, and is consistent with the findings of brain imaging and lesion studies of covert attention and overt saccade production in humans (Nobre et al., 1997; Corbetta, 1998; Mesulam, 1999; Donner et al., 2000). Here, we investigated the neuronal mechanisms underlying changes of performance during popout visual search caused by the repetition of stimulus features and target position. Also, based on measures of neuronal modulation, we evaluated the relative contribution of target representation enhancement and distractor representation suppression to the priming of popout.

\section{MATERIALS AND METHODS}

Subjects and physiological procedures. Data were collected from one Macaca mulatta and one Macaca radiata, weighing 9 and $7 \mathrm{~kg}$, respectively. The animals were cared for in accordance with the National 
A

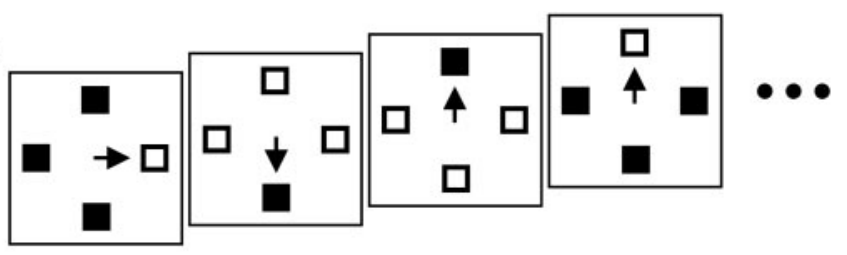

B

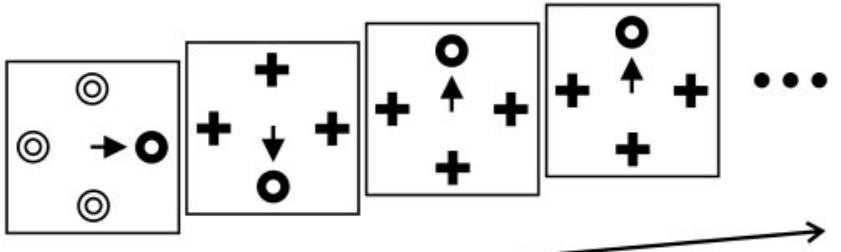

Time

Figure 1. Popout search task. Example sequences of four trials are shown for monkey $\mathrm{F}(A)$ and monkey $\mathrm{C}(B)$. The monkeys' task was to shift gaze to the target stimulus defined as the color singleton. The arrow represents the saccade to the target. Stimuli are not drawn to scale.

Institutes of Health Guide for the Care and Use of Laboratory Animals and the guidelines of the Vanderbilt Animal Care Committee. The surgical procedures for the subconjunctival implantation of a scleral search coil, for the attachment of a stainless steel post to the skull to restrain the head during testing, and for the craniotomy and the placement of a recording chamber over FEF, have been described previously (Schall et al., 1995b; Thompson et al., 1996). All surgical procedures were performed with the use of sterile techniques.

Behavioral procedure. The experiments were under the control of two personal computers using software developed by Reflective Computing (St. Louis, MO), which presented the stimuli, recorded action potentials and eye movements sampled at $1 \mathrm{kHz}$ and $250 \mathrm{~Hz}$, respectively, and delivered the juice reward. Monkeys were seated in an enclosed chair within a magnetic field to monitor eye position with a scleral search coil. Stimuli were presented on a video monitor $(70 \mathrm{~Hz}$ non-interlace, $800 \times$ 600 resolution) viewed binocularly at a distance of $57 \mathrm{~cm}$ in a dark room. The background was uniform dark gray [Commission Internationale de l'Eclairage (CIE) $x=205, y=234$; luminance, $\left.0.1 \mathrm{~cd} / \mathrm{m}^{2}\right]$, and the fixation spot was a white $\left(30 \mathrm{~cd} / \mathrm{m}^{2}\right)$ square. For monkey $\mathrm{F}$, the stimuli were either red (CIE, $x=623, y=339)$ or green (CIE, $x=277, y=611$ ) filled squares matched for luminance $\left(5.8 \mathrm{~cd} / \mathrm{m}^{2}\right)$. For monkey $\mathrm{C}$, the stimuli were either red (CIE, $x=621, y=345$ ) or green (CIE, $x=279$, $y=615)$ matched for luminance $\left(2.3 \mathrm{~cd} / \mathrm{m}^{2}\right)$, and could be either crosses or outline circles.

Each experimental session started with a block of $\sim 150$ detection trials that were used to map the response field of neurons. Each detection trial began with the presentation of a central fixation point. After an interval of fixation $(\sim 500 \mathrm{msec})$, the target stimulus was presented, and monkeys were rewarded for making a single saccade to it.

For monkey $\mathrm{F}$, the procedure for popout search trials (Fig. 1A) was essentially the same as for the detection trials except that the target was presented among three distractors that differed from it in color (i.e., red target among green distractors or green target among red distractors). The stimuli, spaced evenly on the circumference of an imaginary circle around the central fixation point, were placed such that one stimulus always fell in the center of the receptive field of the neuron. The color of the target and distractors switched across trials with a probability of 50 or $33 \%$, or in blocks of 10 trials; the three different switch probabilities were pseudorandomly intermixed within each recording session. The monkey was rewarded for making a single saccade to the target and maintaining gaze at its position for $500 \mathrm{msec}$. If the monkey broke fixation before stimulus presentation, made a saccade to a location other than the target, made a saccade to the target but failed to fixate it for the prescribed period, or did not initiate a saccade within $2 \mathrm{sec}$ of target presentation, the trial was immediately aborted, and the monkeys failed to receive the liquid reward. All stimuli were removed from the screen $\sim 40 \mathrm{msec}$ after a trial was aborted. This undermined an analysis of subsequent saccades but encouraged monkeys to find the target on the first saccade.

For monkey $\mathrm{C}$, the procedure for popout search trials (Fig. 1B) was different than for monkey $\mathrm{F}$ in that the properties of the target remained the same within a daily session. This was necessary because data from conjunction search was also being collected from this monkey, which required the target to remain constant within a session (Bichot and Schall, 1999a,b). For this monkey, the priming effect was generated by changing the dimension of the popout search in blocks of 10 trials from a color search (i.e., distractors were of the same shape as the target but their color was different) to a shape search (i.e., distractors were of the same color as the target but their shape was different). The target was presented among three or five distractors. The stimuli were again spaced evenly on the circumference of an imaginary circle around fixation and were placed such that one stimulus always fell in the center of the receptive field of a neuron.

On average, monkeys ran $\sim 800$ popout search trials while recordings were made from each neuron. Example sequences of popout search trials for monkeys $\mathrm{F}$ and $\mathrm{C}$ are shown in Figure 1, $A$ and $B$, respectively. In both these sequences, the second trial represents the first trial after a feature switch, and the next trial represents the second trial after the feature switch; the last trial of the sequence in Figure $1 A$ represents another first trial after a feature switch, and the last trial of the sequence in Figure $1 B$ represents the third trial after the feature switch. Also, in both these sequences the second and third trials represent first trials after a target position change, and the last trial represents the second trial after a target position change (i.e., the target remained in the same position for one trial).

Analysis of the time course and magnitude of neuronal discrimination. We used a method adapted from signal detection theory (Green and Swets, 1966) to determine when and to what degree the activity of neurons discriminated the target from distractors. This method was previously described in Thompson et al. (1996). Briefly, we first generated the spike density function for each correct trial by convolving action potentials with a function that resembled a postsynaptic potential. Spikes occurring after saccade initiation were not included in the calculation of the spike density functions. We then compared, for each neuron separately, the distribution of discharge rates during trials when the target fell in its response field to the distribution of discharge rates during trials when a distractor fell in its response field. The comparison was conducted in nonoverlapping $5 \mathrm{msec}$ bins starting at the time of search array presentation. The separation of the two distributions of activity at each time interval was quantified by calculating receiver operating characteristic (ROC) curves (Green and Swets, 1966; Macmillan and Creelman, 1991) (see also Bradley et al., 1987; Britten et al., 1992). Points on the ROC curve were generated by plotting the fraction of trials when the target was in the response field with activity greater than a criterion as a function of the fraction of trials when a distractor was in the response field with activity greater than that criterion. The entire ROC curve was generated by incrementing the criterion from zero to the maximum discharge rate observed on a single trial in steps of 2 spikes/sec. The area under the ROC curve represents a quantitative measure of the separation of the two distributions of activity. An area under the ROC curve value of 0.5 signifies that the two distributions being compared are completely overlapping (i.e., indistinguishable), whereas a minimum value of 0.0 or a maximum value of 1.0 signify that the two distributions do not overlap at all (i.e., perfectly distinguishable). Thus, the neuronal discrimination process was quantified by plotting the area under the ROC curve as a function of time. Finally, to describe the growth in the area under the ROC curve over time, the data were fit with a cumulative Weibull function:

$$
P=\gamma-(\gamma-\delta) \exp \left[-(t / \alpha)^{\beta}\right]
$$

where $t$ is time from stimulus presentation, $\gamma$ and $\delta$ are the maximum and minimum asymptotic levels of discrimination, respectively, $\alpha$ is the time at which the curve reaches $64 \%$ of its full growth, and $\beta$ is the slope.

To compare the time course and magnitude of neuronal discrimination to the behavioral effect of changing stimulus features or changing the target position, we conducted the above analysis as a function of the trial number after a feature or target position change. The magnitude of the neuronal discrimination for each condition was represented by the maximum asymptotic level reached by the area under the ROC curve (i.e., the $\gamma$ parameter of the cumulative Weibull fit). Potential changes in baseline neuronal discrimination were investigated using the minimum asymptotic level of the area under the ROC curve after stimulus presentation and before the discrimination process took place (i.e., the $\delta$ parameter of the cumulative Weibull fit). The time of target discrimination was determined as the time when the fitted area under ROC curve values 

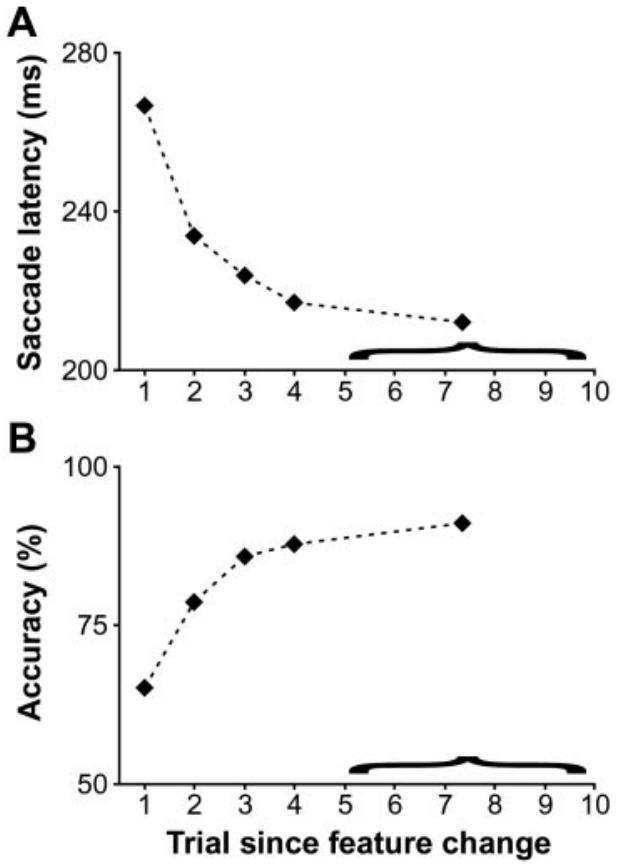

Figure 2. Effect of feature change during popout search on performance. The average of median saccade latency $(A)$ and of accuracy $(B)$ across recording sessions is plotted as a function of trial number relative to the change of stimulus features. Data from five or more trials after the change were combined and are represented by the last point in each plot. The average relative separation of these trials with respect to the feature change was 7.4. Note that accuracy always exceeded chance probability of choosing correctly the target, which was $25 \%$ for a display with four items.

reached a threshold level. Because the maximum, and to some extent the minimum, asymptotic level varied across conditions, we determined the threshold level separately for each neuron. The threshold level for each neuron was computed as the midpoint between the largest of the minimum asymptotic levels (i.e., the $\delta$ parameter of the cumulative Weibull fit) across conditions and the smallest of the maximum asymptotic levels (i.e., the $\gamma$ parameter of the cumulative Weibull fit) across conditions. This allowed us to compute the time of target discrimination while neuronal selection was in its transition state during all conditions.

\section{RESULTS}

We recorded from 78 neurons in 73 sessions while monkeys performed a popout search. Of these neurons, 59 had activity that modulated during the task and provided enough data for both the analysis of the effect of target and/or distractor feature change and the analysis of the effect of target position change. Forty-one of the neurons included in the analyses came from monkey $\mathrm{F}$, and 18 came from monkey $\mathrm{C}$. Behavioral observations were limited to trials during which these neurons were recorded to allow for a direct comparison between behavior and neuronal modulation.

\section{Feature-based facilitation of return}

The effect of changing the target and/or distractor features on behavioral performance is shown in Figure 2 for the two monkeys combined. As the number of trials with the same stimulus features increased, performance improved in that saccade latency during correct trials decreased (Fig. 2A) (Page test for ordered alternatives, $z_{\mathrm{L}}=13.8, p<0.0001$ ) and accuracy increased (Fig. $2 B)\left(z_{\mathrm{L}}=13.2 ; p<0.0001\right)$ significantly. Clearly, the largest combined effect was observed on the first trial after the feature change, with an average difference of $32.8 \mathrm{msec}$ in saccade latency and $13.4 \%$ in accuracy compared to the second trial after the change. Furthermore, the benefit obtained from the repetition of the target and distractor features appeared to asymptote after approximately five trials. Thus, the data for trials starting from the fifth after the feature change were combined with a resulting average trial separation from the feature change of 7.4 across the data set. For these trials, the average median saccade latency across all the sessions was $211.9 \mathrm{msec}$, and the average accuracy was $91.0 \%$, an improvement of $\sim 55 \mathrm{msec}$ in saccade latency and $25 \%$ in accuracy compared with the first trial after the change. However, note that accuracy on the first trial after the change was still considerably better than chance (in fact, it was never below chance during any session) (see Fig. $5 A$ ).

The observations above held true for both monkeys, and the effect of feature changes during popout search was significant for each monkey considered separately (monkey $\mathrm{F}$, saccade latency: $\mathrm{z}_{\mathrm{L}}=11.9, p<0.0001$; accuracy: $\mathrm{z}_{\mathrm{L}}=11.5, p<0.0001$; monkey $\mathrm{C}$, saccade latency, $\mathrm{z}_{\mathrm{L}}=7.1, p<0.0001$; accuracy: $\mathrm{z}_{\mathrm{L}}=6.7, p<$ $0.0001)$. Although the overall effect of feature change on saccade latency and accuracy was somewhat smaller for monkey $\mathrm{C}$, the data from the two monkeys were combined for most of the analyses because there were no qualitative differences in the conclusions reached from each data set separately.

The activity of one FEF visuomovement neuron during this task is shown in Figure 3. On the first trial after the feature change, this neuron responded with a latency of $\sim 55 \mathrm{msec}$ after the appearance of the search array (Fig. $3 A$ ). This neuron initially did not discriminate the target from distractors in its response field, but its activity evolved to signal the location of the oddball target before saccades were generated. We quantified the time course and magnitude of the discrimination process using a method adapted from signal detection theory (see Materials and Methods). The result of this analysis is shown in the rightmost column of Figure 3. Initially after the search array presentation, values of the area under the ROC curve remained around 0.5, which reflects the inability of the neuron to distinguish target from distractors. However, at $\sim 200 \mathrm{msec}$ after search array presentation, the values increased sharply and then asymptoted reflecting the transition of the neuron to a state in which the target location has been identified. From the cumulative Weibull function fit, the time of target discrimination was determined to be $217 \mathrm{msec}$, and the asymptotic maximum level of discrimination was determined to be 0.72 . During recordings from this neuron, the median saccade latency on the first trial after the feature change was $301 \mathrm{msec}$, and the accuracy was $61.5 \%$.

In trials increasingly removed from the feature change (Fig. $3 B-E)$, both the time course and magnitude of the target selection exhibited by this neuron changed in parallel with the changes in the monkey's performance. Although the latency of the initial response of the neuron did not change, and the initial response was still not selective, target discrimination occurred increasingly earlier, and the asymptotic level of discrimination was higher. From the second to the fifth trial after the feature change, the time of target discrimination was 131, 125, 117, and $120 \mathrm{msec}$, respectively. The median saccade latency for these conditions was 244, 221, 220, and $218 \mathrm{msec}$, respectively. Thus, changes in the time of target discrimination for this neuron predicted changes in the median saccade latency caused by the feature change. Similarly, the asymptotic discrimination level was $0.76,0.80,0.88$, and 0.89 , respectively, corresponding to the increasing accuracy.

To determine how well the dynamics of the selection process in FEF predicted changes in saccade latencies caused by the feature change, for each neuron we computed the total least-squares 
Target in RF Distractor in RF

A
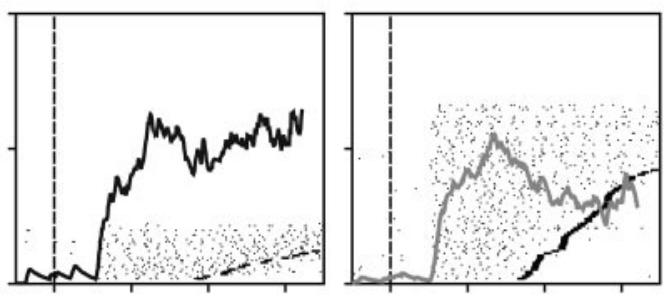

B
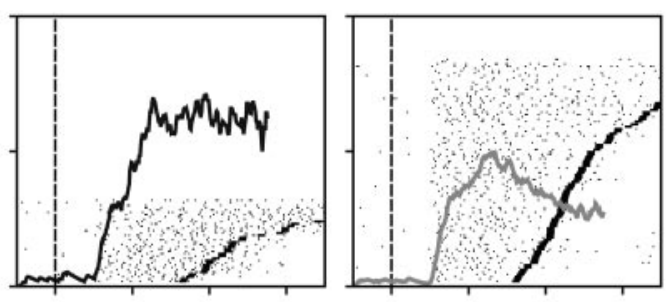

C
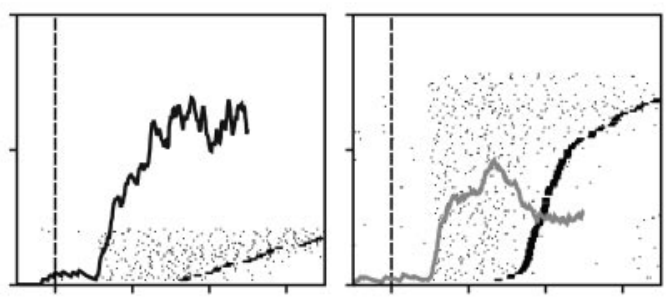

D
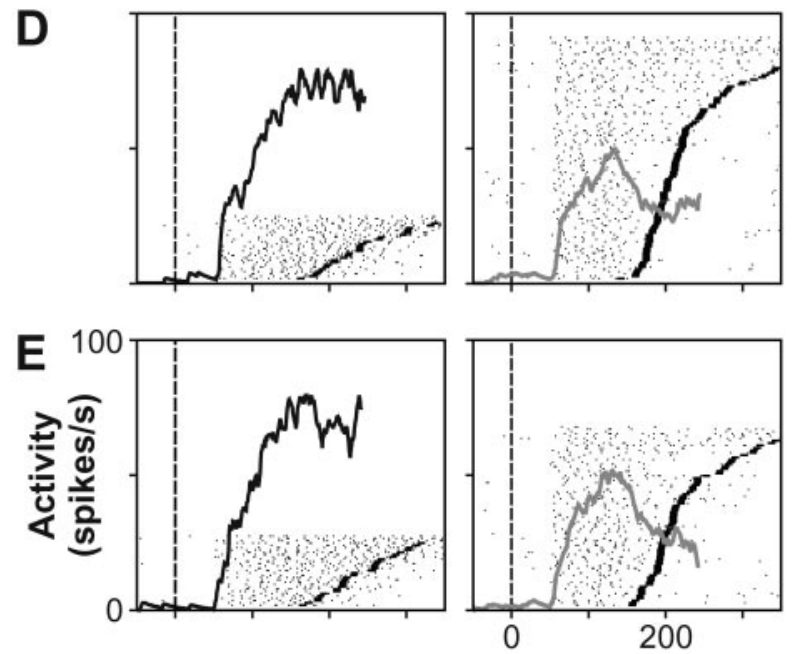
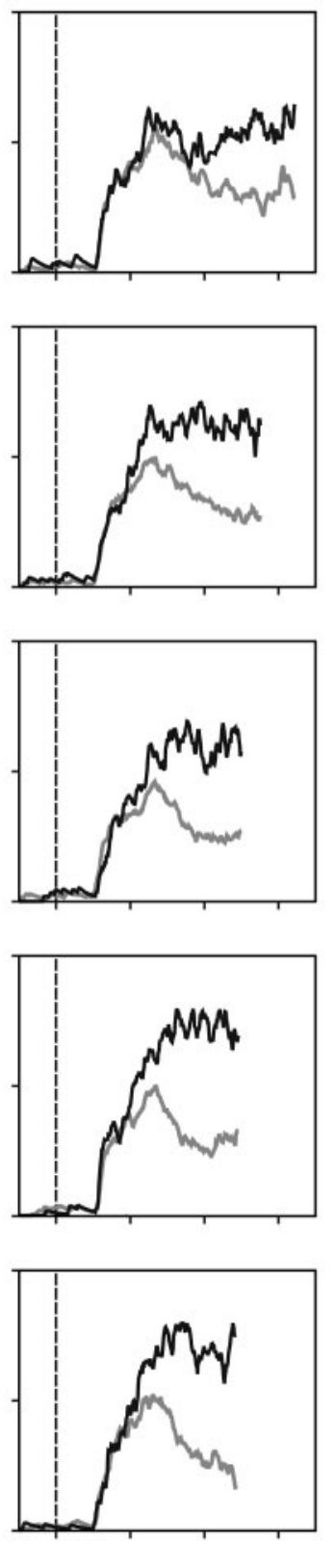

ROC analysis

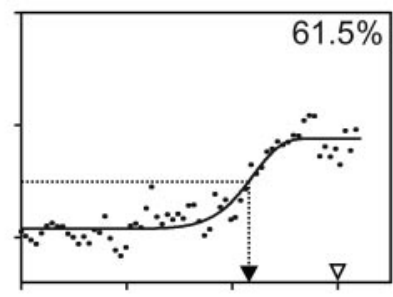

change

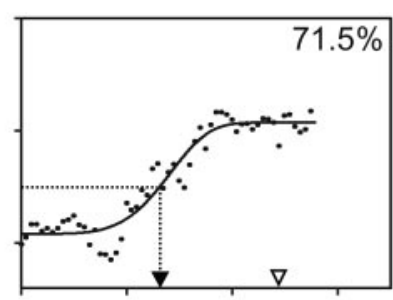

2
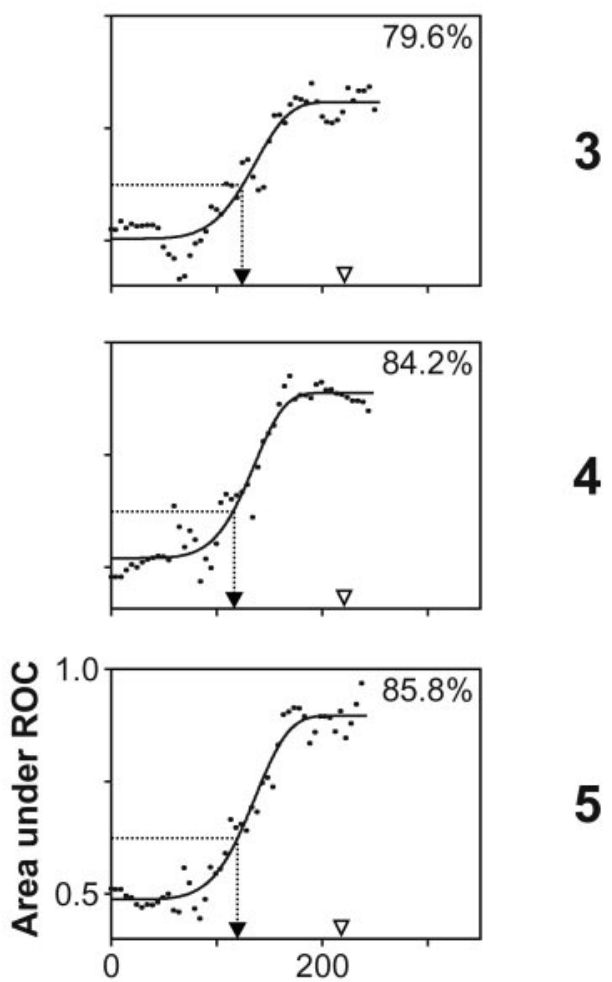

Figure 3. Effect of feature change during popout search on the activity of one FEF visuomovement neuron. Activity is shown as a function of trial number after the feature change laid out in rows $(A-E)$. Thus, each row represents an increasing relative trial position with respect to the feature change, with the first row $(A)$ representing activity during the first trial after the change, and the last row $(E)$ representing activity during the fifth trial after the change. Trials after the fifth following the change were not included for illustration purposes. The first and second columns show raster plots of the activity of the neuron when the target or a distractor of the search array was in its response field $(R F)$, respectively. In these plots, each dot represents the time at which an action potential was recorded, each line of rasters represents the activity on one trial, and the horizontal line in each raster indicates the time of saccade initiation. Rasters are aligned on the time of search array presentation at time 0 (vertical dashed lines) and are sorted by increasing saccade latency. Superimposed on each raster plot is the average spike density function plotted up to the mean saccade latency; the ordinate scale represents the discharge rate. Only correct trials and spikes that occurred before saccade initiation were used in the computation of the spike density functions and all subsequent analyses. The spike density function of the neuron when the target (black) and distractors ( gray) of the search array fell in its receptive field are superimposed in the third column. The rightmost column shows the result of the ROC analysis comparing the distribution of discharge rates during trials when the target fell in the response field of the neuron to the distribution of discharge rates when distractors fell in its response field. In each plot, the vertical dotted line with an arrow pointing toward the abscissa marks the time of target discrimination, which was calculated based on a common threshold used across all trial repetition conditions (see Materials and Methods). The top right corner of each plot shows the percentage of trials the monkey performed correctly for that condition while the neuron was recorded; the arrowhead above the abscissa marks the median saccade latency for that condition. 

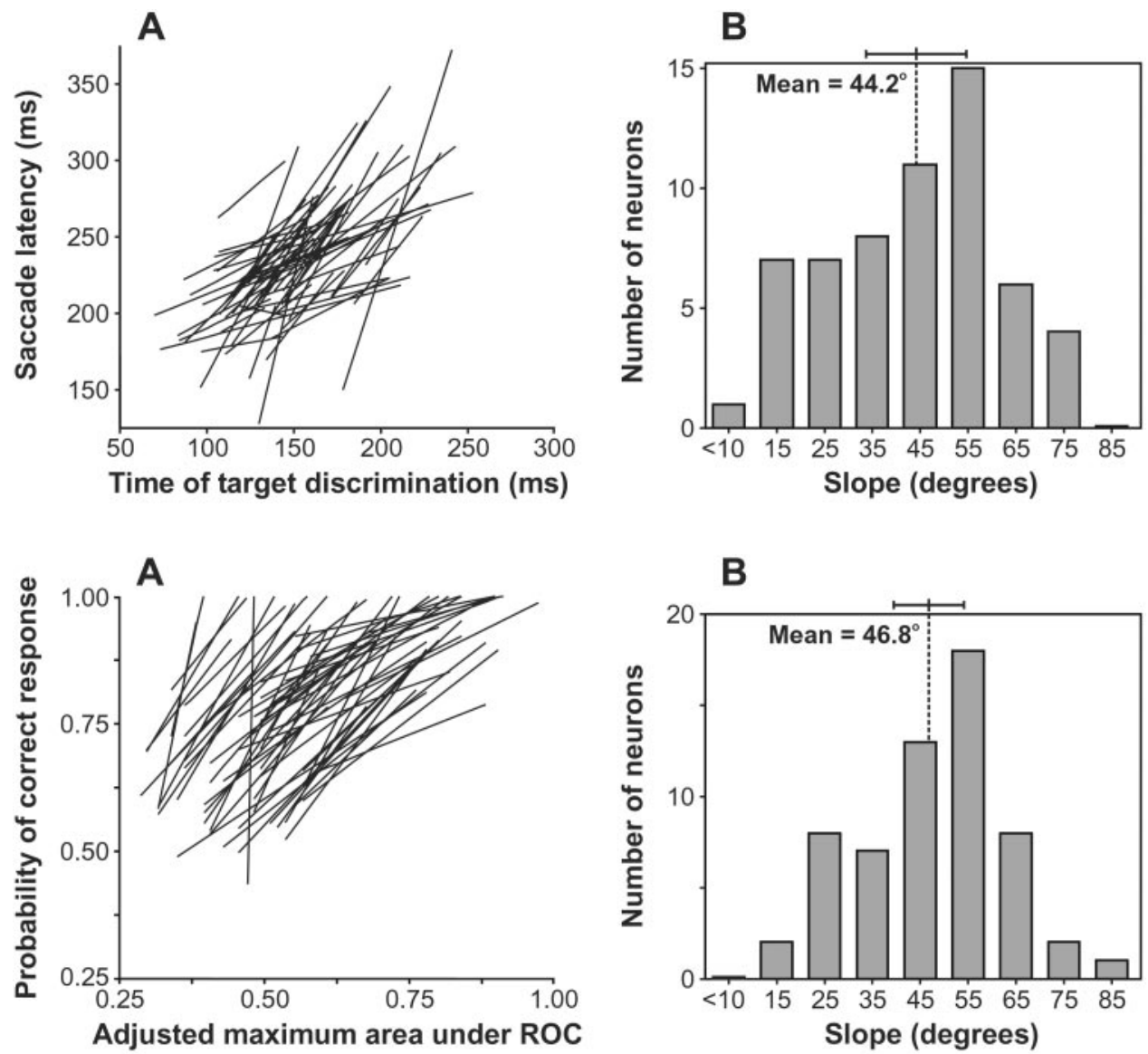

Figure 4. Summary of the relationship between the effect of changing stimulus features on the time course of neuronal discrimination and on saccade latency. For each neuron, we plotted the median saccade latency for each of the five groups of trials described in Figure 2 as a function of the time of neuronal target discrimination for that group of trials (see Materials and Methods). We then determined the total least-squares best-fit line across those five data points. The resulting line for each neuron is plotted in the left panel $(A)$. The right panel $(B)$ shows the distribution of the angular slope of the best-fit lines. The mean and $95 \%$ confidence interval are shown. The strong tendency was a one-to-one relationship.

Figure 5. Summary of the relationship between the effect of changing stimulus features on the maximal level of neuronal discrimination and on accuracy. For each neuron, we plotted the percentage of correct trials for each of the five groups of trials described in Figure 2 as a function of the maximal asymptotic level of neuronal target discrimination reached for that group of trials (see Materials and Methods). We then determined the total least-squares best-fit line across those five data points. The resulting line for each neuron is plotted in the left panel $(A)$. The right panel $(B)$ shows the distribution of the angular slope of the best-fit lines. The mean and $95 \%$ confidence interval are shown. The clear tendency was a one-to-one relationship. regression between the measured time of target discrimination and the median saccade latency across the five trial repetition conditions with respect to the feature change described in Figure 2. We then converted the slope of the regression to an angular value. Thus, an angle of $45^{\circ}$ (slope of 1 ) signifies a one-to-one relationship between the change in the time of neuronal target discrimination and the change in median saccade latency. On the other hand, a slope of $90^{\circ}$ (infinite slope) signifies that the change in the time of neuronal target discrimination cannot predict the change in median saccade latency. For the neuron in Figure 3, the angle of the total least-squares regression between these two measures was $40.0^{\circ}$.

We applied this regression analysis to all 59 neurons; the resulting total least-squares regression lines are shown in Figure $4 A$. The distribution of the angles of these lines is shown in Figure $4 B$. For the majority of neurons, the change in time of target discrimination predicted well the change in median saccade latency (i.e., slopes of $\sim 45^{\circ}$ ). Also, there was no evidence of bimodality in the distribution of the slopes. Using circular statistics (Batschelet, 1981), the average slope was determined to be $44.2^{\circ}$. A $V$-test was performed on the angular data to determine whether the observed angular slopes clustered around the criterion slopes of $45^{\circ}$ (i.e., perfect predictability) and $90^{\circ}$ (i.e., no predictability). The angles of the lines were significantly clustered around $45^{\circ}\left(V\left(45^{\circ}\right)_{58} ; u=8.7 ; p<0.0001\right)$, but not around $90^{\circ}$ $\left(V\left(90^{\circ}\right)_{58} ; u=0.3\right)$. Thus, the observed angles deviate significantly from randomness and reveal a strong relationship between the time of neuronal target discrimination and median saccade latency across stimulus feature repetition. On average across all trial conditions, the time of neuronal target discrimination preceded the median saccade latency by $\sim 82 \mathrm{msec}$.

We also calculated the total least-squares regression analysis comparing the maximum neuronal discrimination level achieved with the accuracy performed (Fig. 5) across the same five feature repetition conditions. However, before computing the regression, the maximum asymptotic discrimination indices (i.e., area under ROC curve values) were adjusted for the number of stimuli in the displays. An ROC analysis is typically conducted for twoalternative forced-choice experiments, and the area under the unbiased ROC curve equals accuracy (e.g., an area under the ROC curve value of 0.5 signifies a $50 \%$ correct choice percentage). However, our displays typically presented four choices, so the values of area under the ROC curve we obtained in the neuron-antineuron analysis assuming a two-alternative forcedchoice design no longer relate directly to the observed accuracy with more than two choices. Thus, we converted the area under the ROC curve values to their equivalent for the actual number of choices in the display using the conversion table provided by Hacker and Ratcliff (1979) and the algebraic approximations to the tabled values by Smith (1982) (see also Macmillan and Creelman, 1991).

For the neuron in Figure 3, the angle of the total least-squares regression between the adjusted asymptotic area under the ROC curve and behavioral accuracy was $40.2^{\circ}$. Across the population, the mean angular slope of the regression lines was $46.8^{\circ}$, and there was no evidence of bimodality in the distribution of the slopes. The angles of the lines were significantly clustered around $45^{\circ}$ $\left(V\right.$-test, $\left.V\left(45^{\circ}\right)_{58} ; u=9.3 ; p<0.0001\right)$, but not around $90^{\circ}$ 
$\left(V\left(90^{\circ}\right)_{58} ; u=0.6\right)$. Thus, changes in levels of neuronal discrimination predicted changes in accuracy caused by feature repetition. However, absolute neuronal performance at the singleneuron level was not sufficient to account for behavioral accuracy. The average adjusted maximum neuronal discrimination index across the five trial conditions was 0.59 , significantly underestimating the observed probability of correct responses of 0.82 (Wilcoxon signed ranks test; $z_{294}=14.7 ; p<0.0001$ ). Bichot et al. (2001) showed that combining the activity of $<10$ neurons can account for accuracy during visual search tasks.

We also investigated the possibility that differential activity before array presentation changed as target and distractor features repeated. We found that this was not the case: the mean, nonadjusted baseline discrimination level (see Materials and Methods) of 0.49 did not vary with trial position relative to the feature change (Friedman test; $F_{\mathrm{r}}=1.7$; df $=4 ; p>0.05$ ).

Finally, we investigated whether the behavioral improvements observed with repetition of the target and distractor features were mediated by target enhancement or distractor suppression. For each neuron, we measured average target-related and distractorrelated activation when the discrimination process was for the most part completed, or in other words, from the end of the transition period in the discrimination process to the mean saccade latency. The beginning and end of the transition period were estimated from the rate of change of the Weibull function used to fit the area under the ROC curve values as a function of time from search array presentation (Fig. $3 A-E$, rightmost column). Across all neurons, the end of the transition occurred on average $53 \mathrm{msec}$ before the mean saccade latency and did not depend on the trial position relative to the feature change (Friedman test; $\left.F_{\mathrm{r}}=3.9 ; \mathrm{df}=4 ; p>0.05\right)$. We concentrated our analysis on two trial conditions: the first two trials after the feature change when accuracy was relatively impaired (i.e., early trials), and the fourth or later trials when the effect of the feature change was greatly diminished (i.e., late trials).

When neuronal discrimination is in its steady-state, a target enhancement mechanism predicts that as accuracy increases, the difference between target and distractor activation increases because of an increase in target activation and no significant change in distractor activation. On the other hand, a distractor suppression mechanism predicts that the difference between target, and distractor activation increases because of a relative decrease in distractor activation and no significant change in target activation. However, because the nature of the feature changes for the two monkeys was different, one may suppose that although both mechanisms contributed to the search when target and distractor colors were switched (i.e., task ran by monkey F), only target enhancement played a role when the target remained constant and only distractor features changed (i.e., task ran by monkey C) (Maljkovic and Nakayama, 1994).

Indeed, we found that both mechanisms contributed to finding the target in the popout search task we implemented for monkey F. Across all neurons recorded from this monkey, the mean target activation of 71.2 spikes/sec measured in the late trials was significantly greater than the mean target activation of 65.9 spikes/ sec in the early trials (Wilcoxon signed ranks test; $z_{40}=2.7 ; p<$ 0.01 ), and the mean distractor activation of 36.5 spikes/sec in the late trials was significantly less than the mean distractor activation of 40.1 spikes $/ \mathrm{sec}$ in the early trials $\left(z_{40}=2.8 ; p<0.01\right)$. Furthermore, there was no overall difference in the magnitude of the target enhancement and distractor suppression effects $\left(z_{40}=0.5\right)$, reflecting equal contributions of these two mechanisms to the

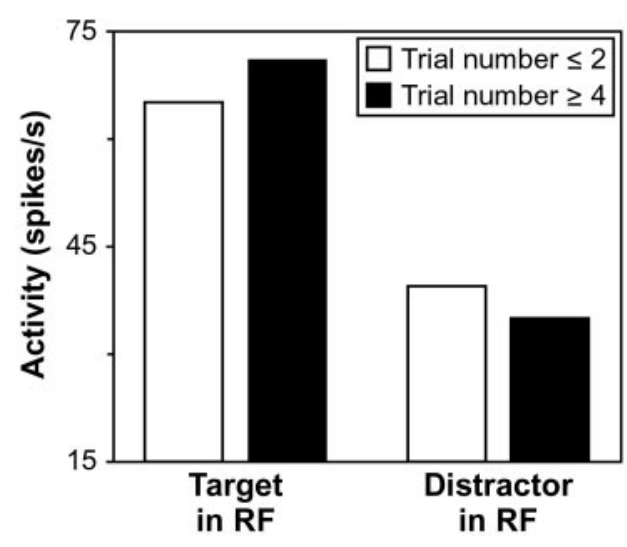

Figure 6. Target enhancement and distractor suppression during feature priming. Average neuronal activity was computed when neurons were in a steady state of discrimination. Average activation in response to the target in the response field $(R F)$ of a neuron and to distractors in the response field of a neuron is shown during the first two trials after the feature change (white bars) and during the fourth and later trials after the feature change (black bars).

search process. We found that both mechanisms also contributed to finding the target in the popout search task we implemented for monkey C. Across all neurons recorded from this monkey, the mean target activation of 71.0 spikes/sec over the late trials was significantly greater than the mean target activation of 63.7 spikes/sec over the early trials (Wilcoxon signed ranks test; $z_{17}=$ $2.1 ; p<0.05$ ), and the mean distractor activation of 31.4 spikes/ sec over the late trials was significantly less than the mean distractor activation of 37.9 spikes/sec over the early trials $\left(z_{17}=3.2\right.$; $p=0.001)$. Furthermore, again there was no difference in the magnitude of the target enhancement and distractor suppression effects $\left(z_{17}=0.2\right)$.

The target enhancement and distractor suppression we observed across both monkeys is summarized in Figure 6. We investigated whether the magnitude of these effects was different between the two monkeys. To make such a comparison, we normalized the firing rates for each neuron by the average firing rate obtained for that neuron across both measured target activations and both measured distractor activations. We found that neither target enhancement (Wilcoxon-Mann-Whitney $U$ test; $\left.z_{58}=0.4 ; p>0.05\right)$ nor distractor suppression $\left(z_{58}=1.6 ; p>\right.$ $0.05)$ differed significantly between the two monkeys.

\section{Location-based inhibition of return}

The effect of target position repetition is shown in Figure 7. Unlike the repetition of features, repetition of the target position over consecutive trials increased saccade latencies significantly (Fig. 7A) (Page test for ordered alternatives, $z_{\mathrm{L}}=5.8 ; p<0.0001$ ) and did not affect accuracy (Fig. $7 B)\left(\mathrm{z}_{\mathrm{L}}=1.1 ; p>0.05\right)$. Unfortunately, we could not determine the full time course of this effect as there were not enough trials to evaluate accurately behavioral performance for conditions in which the target remained in the same position for more than two trials. Furthermore, the number of trials during which the target remained at the same position for two trials (last point in the plots of Fig. 7) was not sufficient to conduct a reliable analysis of target discrimination for many neurons. Thus, we combined trials in which the target remained in the same position for one or two trials (last two points in the plots of Fig. 7).

The average median saccade latency of $218.1 \mathrm{msec}$ on trials in 

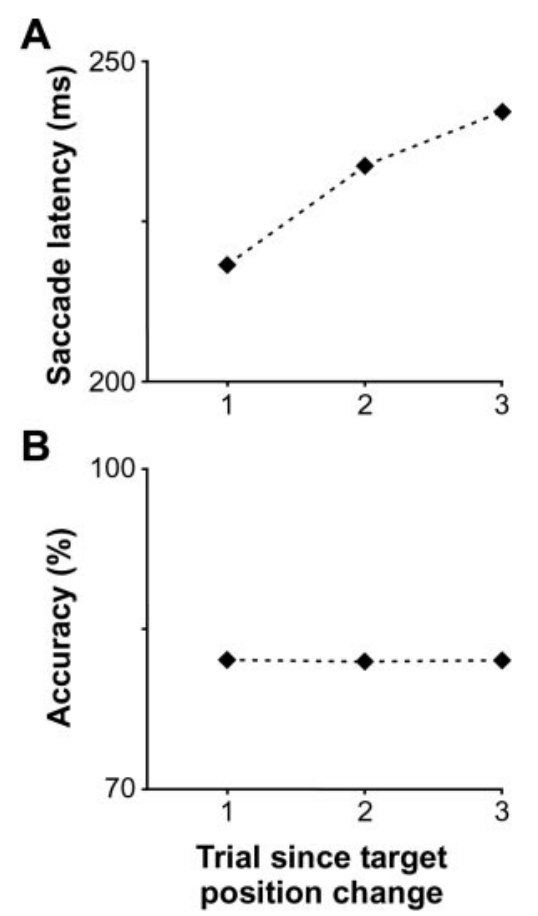

Figure 7. Effect of popout target position repetition on performance. The average of median saccade latency $(A)$ and of accuracy $(B)$ across sessions is plotted as a function of trial number relative to a change in target position.

which the target position changed relative to the previous trial was significantly less than the average median saccade latency of $235.2 \mathrm{msec}$ on all trials in which the target position remained the same relative to the previous trial (Wilcoxon signed ranks test; $\left.z_{58}=6.4 ; p<0.0001\right)$. However, accuracy was not significantly affected by the repetition of target position across trials $\left(z_{58}=\right.$ 0.5 ). These observations were true for both monkeys (monkey $\mathrm{F}$, saccade latency: $z_{40}=5.5, p<0.0001$; accuracy: $z_{40}=0.2, p>$ 0.05; monkey C, saccade latency: $z_{17}=2.9, p<0.01$; accuracy: $\left.z_{17}=1.4, p>0.05\right)$. We combined the data from the two monkeys for the subsequent analyses.

The effect of target position repetition on the activity of an FEF neuron is shown in Figure 8. This is the same neuron depicted in Figure 3. The analysis of the time course of the discrimination process exhibited by this neuron showed that discrimination occurred $28 \mathrm{msec}$ earlier on trials in which target position changed relative to the previous trial (Fig. $8 \mathrm{~A}$ ) compared with trials in which target position remained the same across trials (Fig. 8B). For comparison, during recordings from this neuron, the mean saccade latency increased $52 \mathrm{msec}$ across the same trial conditions.

To investigate whether changes in the dynamics of the selection process in FEF caused by the repetition of the target position predicted changes in saccade latencies, we plotted for each neuron the median saccade latency as a function of the measured time of target discrimination for the two trial conditions of Figure 8. The line segments formed by these two points for each neuron are plotted in Figure $9 A$. For the neuron in Figure 8, the angle of this line was of $61.7^{\circ}$. The distribution of the angles of these lines is shown in Figure $9 B$. The average angle was $44.9^{\circ}$, and the angles of the lines were significantly clustered around $45^{\circ}$ ( $V$-test; $\left.V\left(45^{\circ}\right)_{58} ; u=6.9, p<0.0001\right)$, but not around $90^{\circ}\left(V\left(90^{\circ}\right)_{58} ; u=\right.$ $0.1)$. Thus, the results show a strong relationship between changes

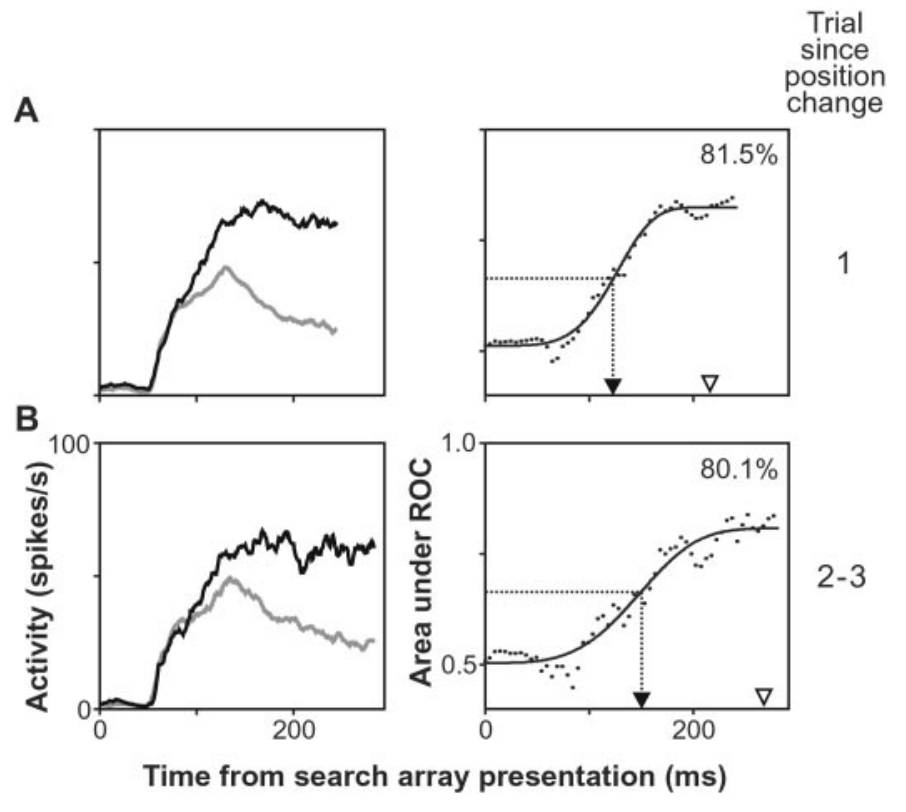

Figure 8. Effect of target position change during popout search on the activity of the FEF visuomovement neuron depicted in Figure 3. The first row of plots $(A)$ illustrates activity during trials in which the target position changed. The second row of plots $(B)$ shows activity during trials in which the target position remained the same with respect to the previous trial. The spike density function of the neuron when the target (black) and distractors ( gray) of the search array fell in its receptive field are superimposed in the left column. The right column of plots shows the result of the ROC analysis comparing the distribution of discharge rates during trials when the target fell in the response field of the neuron to the distribution of discharge rates when distractors fell in its response field. Conventions as in Figure 3.

in the time of neuronal target discrimination and changes in median saccade latency with target position repetition. On average, the time of neuronal target discrimination preceded the median saccade latency by $\sim 79 \mathrm{msec}$.

During recordings from a number of the neurons, changes in median saccade latencies related to the repetition of target position were not very large (i.e., small line segments in Fig. 9), potentially compromising the reliability of the slope angle measurements for those neurons. We analyzed the relationship between the time of target discrimination and median saccade latency separately for neurons that were recorded when the difference in median saccade latency between the two conditions was at least $15 \mathrm{msec}$ (26 neurons) and for neurons that were recorded when the difference in median saccade latency was $<15$ msec (33 neurons). The angles of the lines for both groups of neurons were still significantly clustered around $45^{\circ}\left(V\left(45^{\circ}\right)_{25} ; u=\right.$ 5.9; $p<0.0001 ; V\left(45^{\circ}\right)_{32} ; u=4.0 ; p<0.0001$, respectively), although as expected, the dispersion of slopes was greater for neurons that were recorded when the difference in median saccade latency was $<15$ msec.

Furthermore, consistent with a lack of an effect of target position repetition across trials on accuracy, the maximum asymptotic level of discrimination was also not affected by whether the target position changed or remained the same across consecutive trials (Wilcoxon signed ranks test; $z_{58}<0.1$ ). The lack of a change in the asymptotic level of discrimination prevented the assessment of the contribution of target enhancement and distractor suppression to location-based inhibition of return.

We also investigated the possibility that the baseline discrimi- 
Figure 9. Summary of the relationship between the effect of repeating the target location on the time course of neuronal discrimination and on saccade latency. For each neuron, we plotted the median saccade latency for each of the two groups of trials described in Figure 8 as a function of the time of neuronal target discrimination for that group of trials. The line connecting these two points is plotted for each neuron in the left panel $(A)$. The right panel $(B)$ shows the distribution of the angular slope of these lines. The mean and 95\% confidence interval are shown.

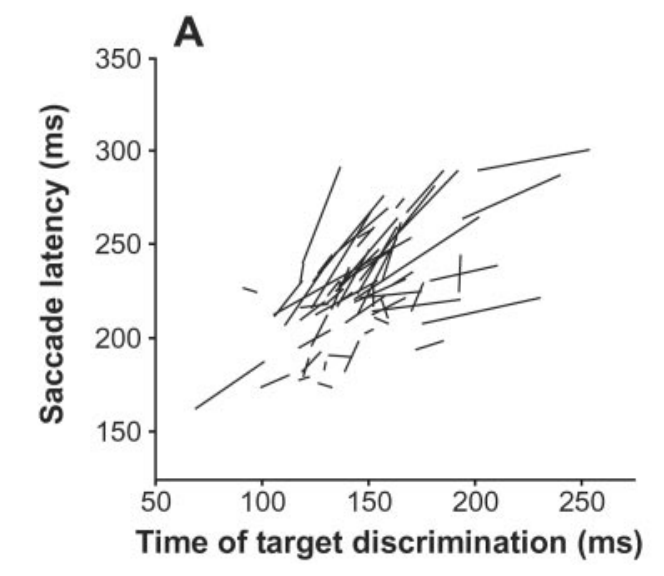

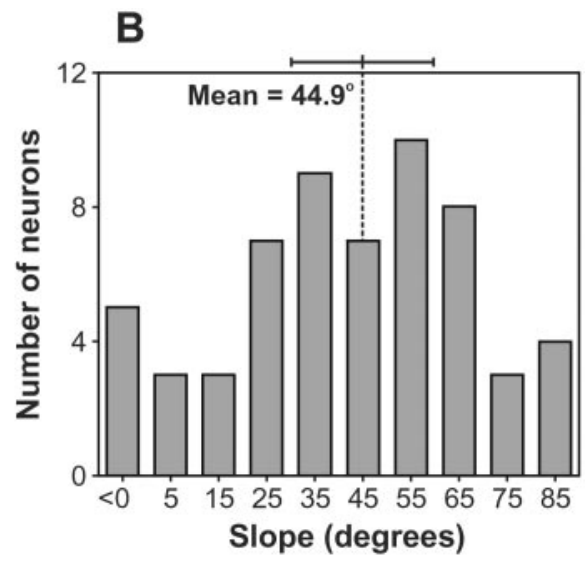

nation ability of the neurons was changed as target position remained the same across consecutive trials. As with the feature change effect, we found that this was not the case: the mean, nonadjusted baseline discrimination level of 0.50 was not affected by target position repetition across trials (Wilcoxon signed ranks test; $\left.z_{58}=0.7\right)$.

\section{DISCUSSION}

In this study, we investigated the neuronal correlates of rapid changes in behavior caused by short-term priming during a popout search task. We found that monkeys were affected by both changes in stimulus features and changes in target position, although the latter effect was weaker. The repetition of target and distractor features over trials significantly shortened reaction time and improved accuracy. In contrast to the facilitation of return effect with feature repetition, we found that the repetition of target position led to an inhibition of return, whereby reaction time was elevated when the target position repeated across consecutive trials.

We found that the properties of the neuronal selection signals in FEF could explain changes in behavior due to both the featurebased facilitation of return and the location-based inhibition of return. This study is, to our knowledge, the first to describe neuronal correlates of short-term feature-based positive perceptual priming and location-based negative priming during popout search. We also found that neuronal discrimination before array presentation was not affected by either feature or target position changes across trials, unlike the changes found by Luck et al. (1997) in early visual areas using a spatial cueing paradigm. Furthermore, we found that even though changes in neuronal discrimination levels predicted well changes in behavioral accuracy, their absolute values significantly underestimated accuracy.

Finally, this study also enabled us to test physiologically the relative contributions of target enhancement and distractor suppression to the search process, mechanisms that until now have only been probed indirectly using behavioral measures. We found both mechanisms contributed to similar extents to finding the target in our popout search tasks.

\section{Relationship to previous behavioral studies of visual selection and priming}

The beneficial effect of target and distractor feature constancy during popout search has been documented in humans in tasks that involve shifts of attention (Bravo and Nakayama, 1992; Maljkovic and Nakayama, 1994) and tasks that involve eye movements (McPeek et al., 1999). This short-term feature priming effect has also recently been demonstrated in macaque monkeys (Bichot and Schall, 1999a; McPeek and Keller, 2001).

The effect on performance of target position repetition across trials appears to be much less consistent from study to study. For example, unlike in our study, Maljkovic and Nakayama (1996) showed priming for target position in human subjects performing a popout search task, similar to the priming for stimulus features (Maljkovic and Nakayama, 1994). Facilitation occurred when the target position was repeated across consecutive trials, and inhibition occurred when the target fell on a position previously occupied by a distractor. The inhibition when the target falls on a position previously occupied by a distractor, sometimes also referred to as "negative priming", has been observed in many studies (Tipper et al., 1990). Avoiding design imbalances in some previous studies, Christie and Klein (2001) replicated the negative effect on performance when the target occupies a distractor position from the previous trial. However, they also found a cost when the target position was repeated, concluding that a more general inhibition of return mechanism was operating, whereby inhibition is applied to any location that contained a stimulus, whether that stimulus was attended or ignored. However, their findings cannot be related directly to ours because the comparisons in their study were with control trials in which the target could appear at a previously unoccupied location.

More relevant to our study are experiments by Tanaka and Shimojo $(1996,2000)$ that, using both single stimulus and color popout search displays, showed different effects of target location repetition, depending on the response required from subjects (see also Dorris et al., 1999). When the task involved spatial orienting (i.e., presence/absence judgment or location judgment), repetition of target location led to an increase in response time, but when the task required the discrimination of a target feature (e.g., color or shape), repetition of target location led instead to a reduction in response time. These results may explain the apparent discrepancy between the negative location repetition effect we found here and the positive effect found by Maljkovic and $\mathrm{Na}$ kayama (1996). In the experiments of Maljkovic and Nakayama (1996), subjects were required to respond to a feature of the color popout target, consistent with the facilitation effect found by Tanaka and Shimojo $(1996,2000)$ in feature discrimination tasks. On the other hand, in our experiment, monkeys responded by making a saccade to the oddball item, consistent with the inhibition found by Tanaka and Shimojo $(1996,2000)$ in spatialorienting tasks. Thus, it appears that the behavior of our monkeys 
is similar to that of humans in response to both feature repetition and location repetition during popout search.

An important question in studies of visual search has been whether the selection of the target stimulus is mediated by an enhancement of the target representation or a suppression of distractor representations. Much of the research in visuospatial attention has been driven by the spotlight metaphor (Posner et al., 1980), usually with the implicit or explicit assumption that attention operates by facilitating processing in a selected region of the visual field (for review, see Cave and Bichot, 1999). In contrast, using a spatial probe technique, Cepeda et al. (1998) concluded that selection during a color popout search was mediated by the suppression of distractor information, consistent with the attentional modulation observed in the activity of cortical neurons (for review, see Desimone and Duncan, 1995). Maljkovic and Nakayama (1996) also addressed this question in relation to the feature priming effect they observed. They tested for target enhancement by keeping the target color constant and changing the distractor color across trials, and they tested for distractor suppression by keeping the distractor color constant and changing the target color across trials. They found that priming occurred in both tasks, but that target color repetition resulted in larger benefits, suggesting a greater contribution of target facilitation. Here, we tested directly the contribution of these two mechanisms to the priming of popout using measures of neuronal modulation. We found that both target enhancement and distractor suppression contributed to the effect, but we did not find a significant difference in the magnitude of their respective contributions. Moreover, in the task where the target remained constant and only distractor features changed (i.e., monkey $\mathrm{C}$ ), we again found that both mechanisms contributed equally to the priming effect, raising doubts about the necessity of the assumptions made by Maljkovic and Nakayama (1996) in their experimental design to probe each mechanism in isolation.

\section{Relationship to previous physiological studies of visual selection in FEF and other areas}

We have shown previously that experience can affect both the behavior of monkeys and neuronal modulation in FEF during a popout search (Bichot et al., 1996). Monkeys trained with both complements of a color popout search display (i.e., red target among green distractors and vice versa) generalized to a strategy of looking for the oddball stimulus, whereas monkeys trained exclusively with one complement adopted a strategy of ignoring stimuli with the distractor color, even when the same color defined the target in the complementary search array presented occasionally. Approximately half of the neurons in the monkeys trained exclusively with one color combination showed an unprecedented selectivity in their initial response.

The feature perceptual priming we describe here differs from the effects in that study in several ways. First, although the control monkeys in our earlier study were trained with both complements of the color search array, they performed search with each of the complementary arrays in long blocks that sometimes spanned an entire session. Thus, their behavior would have been similar to trials in our current study during which behavior was stable. Thus, the effect we observed in the experimental monkeys in our earlier study appears to be caused by a long-term effect of experiencing a particular color combination. Second, in our previous study we had used display sizes of eight stimuli, and the perceptual priming effect reduces with increasing display size (Maljkovic and $\mathrm{Na}$ kayama, 1994; McPeek et al., 1999). Consistent with an interpre- tation that the earlier effect we observed was not caused by short-term perceptual priming, there was no significant difference in reaction time between control and experimental monkeys in contrast to the strong effect we observed here. Finally, whereas the effect of experience on neuronal modulation in our earlier study was mediated by an inhibition of distractor information, in our current study we found that both target enhancement and distractor inhibition mediated the feature priming effect.

Using a conjunction search task, we had also shown previously that activity in FEF can predict an aspect of the history of target features that was reflected in the monkeys' behavior (Bichot and Schall, 1999b). This effect, which we had termed long-term priming, revealed itself as a tendency of monkeys to make saccades to a distractor that was the target during the previous session. However, the time course and nature of this effect was different than the short-term perceptual priming we investigated here. In that study, monkeys searched for one color and shape combination in any given session, and the combination was only changed across sessions. Thus, this effect revealed itself across sessions that were at least $1 \mathrm{~d}$ apart, and persisted throughout the session. In contrast, the effect of changing stimulus features in the popout search display is of much shorter duration, affecting behavior for typically $<10$ trials.

Other studies have also investigated the relationship between behavioral performance and neuronal activity. Among these, studies by Kim and Shadlen (1999) and Shadlen and Newsome (2001) have been conceptually the most directly comparable to ours. They have shown that neurons in the lateral intraparietal area and dorsolateral prefrontal cortex predicted monkeys' judgment on a motion discrimination task and that the timing and magnitude of neuronal responses was affected by the strength of the motion signal to be discriminated. However, like our previous studies of visual selection in FEF (Bichot and Schall, 1999b; Bichot et al., 2001), these studies were concerned about decisions made on the basis of stimulus properties on a given trial, rather than stimulus properties relative to previous trials.

A few studies have examined changes in neuronal modulation as a function of the evolution of behavior within an experimental session (Mitz et al., 1991; Chen and Wise, 1995; Basso and Wurtz, 1998; Nakamura et al., 1998). However, these studies have usually been concerned with changes after training and acquisition of conditional associations or target sequences. In contrast, in our study monkeys had extensive experience with all the displays used during recordings and the oculomotor association remained constant (i.e., saccade to the oddball stimulus). Thus, behavioral and neuronal modulation in our study were not related to learning but rather to visuomotor experience across trials. A recent study by Dorris et al. (1999) has also investigated neuronal modulation in relation to behavioral changes caused by motor experience within the span of several trials. Monkeys performed a gap saccade paradigm, and the latency of their saccades to the peripheral stimulus decreased as its position was repeated over consecutive trials. Dorris et al. (2000) found concomitant changes in the preparatory activity of superior colliculus neurons in advance of the presentation of the peripheral stimulus. In contrast, in our study using a popout visual search task, we found no baseline changes in neuronal discrimination even after target position repetition, but rather found changes in the pattern of neuronal discrimination after stimulus presentation. Potential differences in the behavioral strategy adopted by monkeys as a consequence of differences in experimental paradigms may be the cause of the discrepancy between the findings of these studies. 
We also found that the absolute discrimination performance of individual neurons did not account for the observed accuracy of monkeys. This finding is consistent with the widely held and commonsense view that selection is accomplished by populations rather than individual neurons. Numerous studies, spanning many areas of the brain, have shown that behavior is accounted for by the pooled activity of populations of neurons (Tolhurst et al., 1983; Bradley et al., 1987; Optican and Richmond, 1987; Shadlen et al., 1996; Lee et al., 1998; Takemura et al., 2001). Most directly relevant to our observation here is our recent investigation of neuronal reliability in FEF during visual search experiments (Bichot et al., 2001). Across a variety of search tasks leading to a wide range of search efficiency, we found that the probability of correct responses was approximated when the activity of at least six neurons was combined.

\section{Neuronal sources of repetition priming}

We observed clear correlates of feature repetition priming in FEF, most likely as a result of its extensive network of inputs from both dorsal and ventral stream areas (Schall et al., 1995a; Jouve et al., 1998), as well as prefrontal cortex (Huerta et al., 1987; Stanton et al., 1993). However, because FEF neurons are not typically selective for visual attributes such as color (Mohler et al., 1973), the question remains as to what is the source of the modulation we observed. Several lines of evidence support the view that the feature priming effect originates in the neural networks of the ventral stream, consistent with the fact that neurons in this stream are highly selective for visual features, from basic features such as color and orientation to complex ones (for review, see Desimone et al., 1985; Tanaka, 1996).

The hypothesis that feature priming takes place in areas of the ventral stream is supported by a recent physiological recording study in monkeys showing that behavioral relevance of a stimulus established through training modifies the neuronal representation of that stimulus in inferotemporal cortex (Jagadeesh et al., 2001). More direct evidence comes from Walsh et al. (2000), who investigated the effects of lesions of areas V4 and TEO on feature priming. They found that although monkeys with lesions are unimpaired on a simple color popout task, the priming observed in control monkeys was diminished by lesions of TEO and abolished by lesions of V4. A preliminary report by Rossi et al. (2001) further suggests that priming is generated within local circuits of the temporal cortex without top-down feedback influence from the prefrontal cortex, a region generally considered to play an important role in working memory and cognitive control (for review, see Desimone, 1996; Fuster, 2000; Duncan, 2001; Miller and Cohen, 2001). The apparent lack of cognitive control in behavioral manifestations of priming and the automatic nature of this phenomenon (Maljkovic and Nakayama, 1994; Goolsby and Suzuki, 2001) are consistent with this hypothesis.

\section{REFERENCES}

Basso MA, Wurtz RH (1998) Modulation of neuronal activity in superior colliculus by changes in target probability. J Neurosci 18:7519-7534.

Batschelet E (1981) Circular statistics in biology. New York: Academic.

Bichot NP (2001a) Attention, eye movements, and neurons: linking physiology and behavior. In: Vision and attention (Harris LR, Jenkin MR, eds), pp 209-232. New York: Springer.

Bichot NP (2001b) Neural mechanisms of top-down selection during visual search. 23rd Annual International Conference of the IEEE Engineering in Medicine and Biology Society, Istanbul, Turkey, October.

Bichot NP, Schall JD (1999a) Saccade target selection in macaque during feature and conjunction visual search. Vis Neurosci 16:81-89.

Bichot NP, Schall JD (1999b) Effects of similarity and history on neural mechanisms of visual selection. Nat Neurosci 2:549-554.
Bichot NP, Schall JD, Thompson KG (1996) Visual feature selectivity in frontal eye fields induced by experience in mature macaques. Nature 381:697-699.

Bichot NP, Thompson KG, Rao SC, Schall JD (2001) Reliability of macaque frontal eye field neurons signaling saccade targets during visual search. J Neurosci 21:713-725.

Bradley A, Skottun BC, Ohzawa I, Sclar G, Freeman RD (1987) Visual orientation and spatial frequency discrimination: a comparison of single cells and behavior. J Neurophysiol 57:755-772.

Braun J, Koch C, Davies J (2001) Visual attention and cortical circuits. Cambridge, MA: MIT.

Bravo MJ, Nakayama K (1992) The role of attention in different visualsearch tasks. Percept Psychophys 51:465-472.

Britten KH, Shadlen MN, Newsome WT, Movshon JA (1992) The analysis of visual motion: a comparison of neuronal and psychophysical performance. J Neurosci 12:4745-4765.

Burman DD, Segraves MA (1994) Primate frontal eye field activity during natural scanning eye movements. J Neurophysiol 71:1266-1271.

Cave KR, Bichot NP (1999) Visuospatial attention: beyond a spotlight metaphor. Psychon Bull Rev 6:204-223.

Cepeda NJ, Cave KR, Bichot NP, Kim MS (1998) Spatial selection via feature-driven inhibition of distractor locations. Percept Psychophys 60:727-746.

Chen LL, Wise SP (1995) Supplementary eye field contrasted with the frontal eye field during acquisition of conditional oculomotor associations. J Neurophysiol 73:1122-1134.

Christie J, Klein RM (2001) Negative priming for spatial location? Can J Exp Psychol 55:24-38.

Corbetta M (1998) Frontoparietal cortical networks for directing attention and the eye to visual location: identical, independent, or overlapping neural systems? Proc Natl Acad Sci USA 95:831-838.

Desimone R (1996) Neural mechanisms for visual memory and their role in attention. Proc Natl Acad Sci USA 93:13494-13499.

Desimone R, Duncan J (1995) Neural mechanisms of selective visual attention. Annu Rev Neurosci 18:193-222.

Desimone R, Schein SJ, Moran J, Ungerleider LG (1985) Contour, color and shape analysis beyond the striate cortex. Vision Res 25:441-452.

Donner T, Kettermann A, Diesch E, Ostendorf F, Villringer A, Brandt SA (2000) Involvement of the human frontal eye field and multiple parietal areas in covert visual selection during conjunction search. Eur J Neurosci 12:3407-3414.

Dorris MC, Taylor TL, Klein RM, Munoz DP (1999) Influence of previous visual stimulus or saccade on saccadic reaction times in monkey. J Neurophysiol 81:2429-2436.

Dorris MC, Pare M, Munoz DP (2000) Immediate neural plasticity shapes motor performance. J Neurosci 20:RC52.

Duncan J (2001) An adaptive coding model of neural function in prefrontal cortex. Nat Rev Neurosci 2:820-829.

Fuster JM (2000) Executive frontal functions. Exp Brain Res 133:66-70.

Goolsby BA, Suzuki S (2001) Understanding priming of color-singleton search: roles of attention at encoding and "retrieval." Percept Psychophys 63:929-944.

Green DM, Swets JA (1966) Signal detection theory and psychophysics. New York: Wiley.

Hacker MJ, Ratcliff R (1979) A revised table of d' for M-alternative forced choice. Percept Psychophys 26:168-170.

Huerta MF, Krubitzer LA, Kaas JH (1987) Frontal eye field as defined by intracortical microstimulation in squirrel monkeys, owl monkeys, and macaque monkeys. II. Cortical connections. J Comp Neurol 265:332-361.

Jagadeesh B, Chelazzi L, Mishkin M, Desimone R (2001) Learning increases stimulus salience in anterior inferior temporal cortex of the macaque. J Neurophysiol 86:290-303.

Jouve B, Rosenstiehl P, Imbert M (1998) A mathematical approach to the connectivity between the cortical visual areas of the macaque monkey. Cereb Cortex 8:28-39.

Keating CF, Keating EG (1993) Monkeys and mug shots: cues used by rhesus monkeys (Macacca mulatta) to recognize a human face. J Comp Psychol 107:131-139.

Kim JN, Shadlen MN (1999) Neural correlates of a decision in the dorsolateral prefrontal cortex of the macaque. Nat Neurosci 2:176-185.

Lee D, Port DL, Kruse W, Georgopoulos AP (1998) Neuronal population coding: multielectrode recordings in primate cerebral cortex. In Neuronal ensembles: strategies for recording and decoding (Eichenbaum H, Davis J, eds), pp 117-136. New York: Wiley.

Liversedge SP, Findlay JM (2000) Saccadic eye movements and cognition. Trends Cogn Sci 4:6-14.

Luck SJ, Chelazzi L, Hillyard SA, Desimone R (1997) Neural mechanisms of spatial selective attention in areas V1, V2, and V4 of macaque visual cortex. J Neurophysiol 77:24-42.

Macmillan NA, Creelman CD (1991) Detection theory: a user's guide. New York: Cambridge.

Maljkovic V, Nakayama K (1994) Priming of pop-out: I. Role of features. Mem Cognit 22:657-672. 
Maljkovic V, Nakayama K (1996) Priming of pop-out: II. Role of position. Percept Psychophys 58:977-991.

Maunsell JH (1995) The brain's visual world: representation of visual targets in cerebral cortex. Science 270:764-769.

McPeek RM, Keller EL (2001) Short-term priming, concurrent processing, and saccade curvature during a target selection task in the monkey. Vision Res 41:785-800.

McPeek RM, Maljkovic V, Nakayama K (1999) Saccades require focal attention and are facilitated by a short-term memory system. Vision Res 39:1555-1566.

Mesulam MM (1999) Spatial attention and neglect: parietal, frontal and cingulate contributions to the mental representation and attentional targeting of salient extrapersonal events. Philos Trans R Soc Lond B Biol Sci 354:1325-1346.

Miller EK, Cohen JD (2001) An integrative theory of prefrontal cortex function. Annu Rev Neurosci 24:167-202.

Mitz AR, Godschalk M, Wise SP (1991) Learning-dependent neuronal activity in the premotor cortex: activity during the acquisition of conditional motor associations. J Neurosci 11:1855-1872.

Mohler CW, Goldberg ME, Wurtz RH (1973) Visual receptive fields of frontal eye field neurons. Brain Res 61:385-389.

Nakamura K, Sakai K, Hikosaka O (1998) Neuronal activity in medial frontal cortex during learning of sequential procedures. J Neurophysiol 80:2671-2687.

Nobre AC, Sebestyen GN, Gitelman DR, Mesulam MM, Frackowiak RSJ, Frith CD (1997) Functional localization of the system for visuospatial attention using positron emission tomography. Brain 120:515-533.

Optican LM, Richmond BJ (1987) Temporal encoding of twodimensional patterns by single units in primate inferior temporal cortex. III. Information theoretic analysis. J Neurophysiol 57:162-178.

Posner MI, Snyder CR, Davidson BJ (1980) Attention and the detection of signals. J Exp Psychol Gen 109:160-174.

Rossi AF, Bichot NP, Desimone R, Ungerleider LG (2001) Top-down, but not bottom-up: deficits in target selection in monkeys with prefrontal lesions. J Vision 1:18a.

Schall JD, Morel A, King DJ, Bullier J (1995a) Topography of visual cortex connections with frontal eye field in macaque: convergence and segregation of processing streams. J Neurosci 15:4464-4487.

Schall JD, Hanes DP, Thompson KG, King DJ (1995b) Saccade target selection in frontal eye field of macaque. I. Visual and premovement activation. J Neurosci 15:6905-6918.

Shadlen MN, Newsome WT (2001) Neural basis of a perceptual decision in the parietal cortex (area LIP) of the rhesus monkey. J Neurophysiol 86:1916-1936.

Shadlen MN, Britten KH, Newsome WT, Movshon JA (1996) A com- putational analysis of the relationship between neuronal and behavioral responses to visual motion. J Neurosci 16:1486-1510.

Sheinberg DL, Logothetis NK (2001) Noticing familiar objects in real world scenes: the role of temporal cortical neurons in natural vision. J Neurosci 21:1340-1350.

Smith JEK (1982) Simple algorithms for M-alternative forced-choice calculations. Percept Psychophys 31:95-96.

Stanton GB, Bruce CJ, Goldberg ME (1993) Topography of projections to the frontal lobe from the macaque frontal eye fields. J Comp Neurol 330:286-301.

Takemura A, Inoue Y, Kawano K, Quaia C, Miles FA (2001) Single-unit activity in cortical area MST associated with disparity-vergence eye movements: evidence for population coding. J Neurophysiol 85:2245-2266.

Tanaka K (1996) Inferotemporal cortex and object vision. Annu Rev Neurosci 19:109-139.

Tanaka Y, Shimojo S (1996) Location versus feature: reaction time reveals dissociation between two visual functions. Vision Res 36:2125-2140.

Tanaka Y, Shimojo S (2000) Repetition priming reveals sustained facilitation and transient inhibition in reaction time. J Exp Psychol Hum Percept Perform 26:1421-1435.

Thompson KG (2001) Neural mechanisms of bottom-up selection during visual search. 23rd Annual International Conference of the IEEE Engineering in Medicine and Biology Society, Istanbul, Turkey, October.

Thompson KG, Hanes DP, Bichot NP, Schall JD (1996) Perceptual and motor processing stages identified in the activity of macaque frontal eye field neurons during visual search. J Neurophysiol 76:4040-4054.

Thompson KG, Bichot NP, Schall JD (2001) From attention to action in frontal cortex. In: Visual attention and cortical circuits (Braun J, Koch C, Davies J, eds.), pp 137-157. Cambridge, MA: MIT.

Tipper SP, Brehaut JC, Driver J (1990) Selection of moving and static objects for the control of spatially directed attention. J Exp Psychol Hum Percept Perform 16:492-504.

Tolhurst DJ, Movshon JA, Dean AF (1983) The statistical reliability of signals in single neurons in cat and monkey visual cortex. Vision Res 23:775-785.

Viviani P (1990) Eye movements in visual search: cognitive, perceptual and motor control aspects. In: Eye movements and their role in visual and cognitive processes (Kowler E, ed), pp 353-393. Amsterdam: Elsevier.

Walsh V, Le Mare C, Blaimire A, Cowey A (2000) Normal discrimination performance accompanied by priming deficits in monkeys with V4 or TEO lesions. NeuroReport 11:1459-1462.

Yarbus AL (1967) Eye movements and vision. New York: Plenum. 